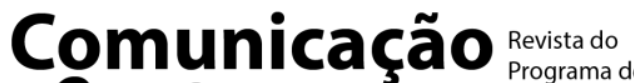

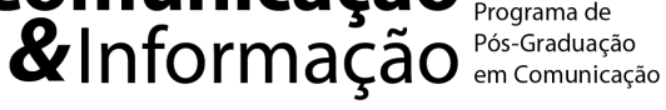

\section{Tecnoestética Algorítmica e Hibridismos Audiovisuais nos Trailers da Netflix}

\author{
Algorithmic Technoaesthetics And Audiovisual Hybridisms In Netflix Trailers
}

\section{Tecno Estética Algorítmica Y Hibridos Audiovisuales En Tráileres De Netflix}

\author{
Stefanie Carlan da Silveira ${ }^{l}$ \\ Patricia Iuva
}

\begin{abstract}
Resumo
As crescentes transformações nas práticas audiovisuais, derivadas dos avanços tecnológicos, delineiam uma diferente paisagem midiática contemporânea cuja estética híbrida aponta, a cada nova relação, para movimentos potenciais alternativos. Diante deste cenário, o estudo aqui apresentado propõe uma reflexão teórica acerca das articulações híbridas e convergentes responsáveis pela construção de uma tecnoestética audiovisual algorítmica na plataforma de streaming Netflix através dos trailers de suas produções originais. $\mathrm{O}$ artigo alicerça a sua discussão teórica a partir das perspectivas teóricometodológicas da Teoria Ator Rede, Teoria dos Sistemas e nos conceitos de espaço híbrido e tecnoestética. O trabalho propõe que se pense numa arqueologia estética do audiovisual, que se manifesta em diferentes territórios da atualidade.
\end{abstract}

Palavras-chave: Trailer. Streaming. Netflix. Algoritmo. Tecnoestética Algorítmica.

\begin{abstract}
The increasing transformations in audiovisual practices, derived from technological advances, outline a different contemporary media landscape whose hybrid aesthetic points, with each new relationship, to potential alternative movements. Given this scenario, the study presented here proposes a theoretical reflection on the hybrid and converging articulations responsible for the construction of an algorithmic audiovisual techno-aesthetic on the Netflix streaming platform through the trailers of their original productions. The article bases its theoretical discussion from the theoretical-methodological perspectives of the Actor Network Theory, Systems Theory and in the concepts of hybrid and technoaesthetic space. The paper proposes to think about an aesthetic archeology of the audiovisual, which is manifested in different territories today.
\end{abstract}

Keywords: Trailer. Streaming. Netflix. Algorithm. Algorithmic Techno-Aesthetic

\begin{abstract}
Resumen
Las crecientes transformaciones en las prácticas audiovisuales, derivadas de los avances tecnológicos, perfilan un paisaje mediático contemporáneo diferente cuya estética híbrida apunta, con cada nueva relación, a potenciales movimientos alternativos. Ante este escenario, el estudio aquí presentado propone una reflexión teórica sobre las articulaciones híbridas y convergentes responsables por la construcción de una tecno estética audiovisual algorítmica en la plataforma de streaming de Netflix a través de los tráileres de sus producciones originales. El artículo basa su discusión teórica desde las

Universidade Federal de Santa Catarina (UFSC), Florianópolis, Santa Catarina, Brasil, me@ @ssilveira.com.

Universidade Federal de Santa Catarina (UFSC), Florianópolis, Santa Catarina, Brasil, patiuva@ gmail.com.
\end{abstract}


perspectivas teórico-metodológicas de la Teoría Actor Red, la Teoría de Sistemas y en los conceptos de espacio híbrido y tecno estética. La obra propone pensar en una arqueología estética del audiovisual, que hoy se manifiesta en diferentes territorios.

Palabras clave: Trailer. Streaming. Netflix. Algoritmo. Tecno Estética Algorítmica.

\section{INTRODUÇÃO}

O cenário contemporâneo é constituído por uma multiplicidade cada vez maior de sistemas comunicacionais. Nesse universo de diversidade, existe uma modalidade discursiva que não está fundada numa palavra, mas sim, numa "sintaxe" de imagens e sons: é o meio audiovisual, o qual constitui o objeto desta reflexão teórica através dos trailers das produções audiovisuais originais da plataforma de streaming Netflix.

A linguagem audiovisual se apropria de códigos, primeiramente aperfeiçoados pelo cinema e depois desenvolvidos pelas tecnologias (do vídeo, da televisão), como, iluminação, som (ruídos/trilha sonora), planos/enquadramentos, montagem, movimento de câmera, tempo e espaço. Assim, a constituição de um produto audiovisual implica na seleção e organização de tais elementos, os quais expressarão uma dada visão estética.

\footnotetext{
A sempre alardeada especificidade cinematográfica parece agora estar se dissolvendo no domínio mais amplo dos meios audiovisuais, sejam estes fotográficos, eletrônicos, sejam cibernéticos, modificando não apenas a 'identidade' do cinema, mas também a de seus consumidores. Na verdade, o desenvolvimento das novas tecnologias audiovisuais representa um impacto dramático sobre praticamente todas as eternas questões enfrentadas pela teoria do cinema: a especificidade, a autoria, a teoria do dispositivo, a espectatorialidade, o realismo e a estética. (STAM; SHOHAT, 2005, p. 415).
}

Isso quer dizer que, de acordo com a tecnologia utilizada, a manipulação dos inúmeros códigos audiovisuais irá constituir conceitos estéticos específicos. Admite-se, assim, o espaço do aparelho (máquina) e do operador (sujeito) na produção do que entendemos como tecnoestética. Em outras palavras, trata-se de um saber fazer cuja natureza intelectual se caracteriza por habilidades de um indivíduo humano, mas também, um fazer caracterizado pelo uso da tecnologia, do ator não-humano, de modo que um dispositivo, aparelho ou máquina é "capaz de encarnar, fora do corpo humano, um saber técnico, um conhecimento científico acerca de habilidades técnicas específicas" (SANTAELLA, 2007, p. 359). Na atualidade, podemos incluir dentre essas máquinas, os códigos que formatam e constituem o ambiente digital, mais especificamente, os algoritmos. Esses códigos constituem e organizam o espaço digital. No âmbito audiovisual, além dos espaços digitais da web, também podemos encontrar essa realidade em plataformas de streaming como Netflix, Amazon Prime Video, 
HBO Go, Globo Play e Apple+. A maioria dessas plataformas funciona a partir da oferta de conteúdo para os usuários, conteúdo este que é curado de forma automatizada a partir do uso de algoritmos.

O cinema, tal como conhecemos, vem perdendo espaço no cenário contemporâneo. Ou melhor, não é o cinema que perde espaço, mas o audiovisual que conquista lugares antes consagrados cinematográficos. Essa conquista, como afirma Dubois (2004), faz com que a estética seja alterada pela especificidade da técnica que nela interfere.

\footnotetext{
Estou falando, é claro, da fotografia, do cinematógrafo, da televisão/vídeo e da imagem informática. Cada uma destas 'máquinas de imagens' encarna uma tecnologia e se apresenta como uma invenção de certo modo radical em relação às precedentes. A técnica e a estética nelas se imbricam, dando lugar a ambigüidades e confusões [...]. (DUBOIS, 2004, p. 33).
}

Acreditamos ser possível pensar em uma estética tecnológica que se funda em expressões audiovisuais extra-fílmicas (tais como a do trailer), considerando que sua produção se dá, hoje, em ilhas de edição auxiliadas por computador, de modo que os "cortes", os planos, as cores, os movimentos, enfim, o acesso à imagem ultrapassa os antigos limites da moviola e do fotograma. As produções audiovisuais não mais apenas se dão através da película, mas por meio de fitas digitais, cartões de memória, HDs externos e computação em nuvem. Assim, as concepções dos produtos audiovisuais são transformadas desde sua origem até o seu fim, de modo que as "leis" do filme (na sua concepção clássica) não se impõem da mesma forma.

[...] todas essas 'máquinas de imagens' pressupõem (ao menos) um dispositivo que institui uma esfera 'tecnológica' necessária à constituição da imagem: uma arte do fazer que necessita, ao mesmo tempo, de instrumentos (regras, procedimentos, materiais, construções, peças) e de um funcionamento (processo, dinâmica, ação, agenciamento, jogo). (DUBOIS, 2004, p. 33).

No que diz respeito aos códigos audiovisuais, vale ressaltar a montagem (edição) como uma das principais operações que dá a ver uma determinada estética tecnológica. Essa montagem, obviamente, leva em consideração o espaço para o qual ela está sendo construída. Montar algo para uma tela de cinema é completamente diferente de montar algo para um serviço de streaming, por exemplo. No primeiro, há uma plateia interessada, em silêncio, cujo objetivo é assistir à obra que está disponível especificamente naquela sala. No segundo, há um espectador que busca "algo para assistir" e precisa ser conquistado pelos primeiros segundos do trailer que passam na tela enquanto o cursor do seu controle "toca" diferentes tipos de obras. Assim, as manifestações audiovisuais contemporâneas são cada vez mais influenciadas 
pelas edições não-lineares fluidas e euforizantes, cujas possibilidades de manipulação dos sons e da imagem ultrapassam as técnicas cinematográficas dos cortes da película. É possível pensar nos trailers enquanto narrativas compósitas, tal como uma composição musical ou poética, que carrega os sentidos de uma estética da produção audiovisual contemporânea influenciada e/ou determinada pelas inovações tecnológicas.

À medida que o mundo digital se embrenha com os sujeitos e a tecnologia se desenvolve, a sua separação do espaço físico e do midiático, antes tão bem delineada, começa a ficar mais nebulosa e pouco nítida (ORBEN, 2013). O imbricamento da conexão ubíqua, das plataformas digitais e dos dispositivos móveis ao comportamento dos sujeitos, faz com que não seja mais possível operar a partir das normas conhecidas e todo um conjunto de processos sedimentados da produção audiovisual passa a não encontrar mais tanto eco dentro das lógicas antigas, principalmente no que se refere à pós-produção e distribuição. Esse novo espaço híbrido (SOUZA E SILVA, 2006) é composto por diferentes regras, entre elas, a operação algorítmica.

O audiovisual, antes tão fundamentado por sistemas de operação tradicionais herdados da cinematografia, precisará funcionar em um ambiente de distribuição e consumo operado por novos agentes não-humanos que são capazes de reorganizar o fluxo de conteúdos entre os sujeitos, priorizar dados, hierarquizar a exposição de publicações, definir quais obras serão mais facilmente acessadas, entre tantas outras funções. Assim, é possível afirmar que

\footnotetext{
O cinema está nos museus, nas galerias de arte, no teatro, na ópera, nas salas de concertos, cada vez mais. Nos bares, nos cafés, nos restaurantes, nas boates. Está nos escritórios, nos locais de trabalho, de passagem ou à espera. Está nas casas, em todos os cômodos. Está nos aviões, nos caminhões, nos táxis, nos trens, nas plataformas das estações de trem. Nos muros das cidades e em nossos telefones celulares. (DUBOIS, 2009 apud GAUDREAULT; MARION, 2016, p. 29).
}

Diante disso, este artigo busca apresentar uma reflexão teórica acerca desse contexto, focando a discussão especificamente na plataforma de streaming Netflix, seu modo de operação através dos trailers de suas produções originais. Procuramos descrever a transformação do sistema midiático audiovisual, propondo uma forma de visualização do atual cenário que leva em consideração a extrema relevância dos atores não-humanos, no intuito de compreender as transformações tecnoestéticas do audiovisual no processo de interação com as regras do espaço algorítmico. Nossa abordagem teórica, baseada em pesquisa bibliográfica, é fundamentada com o auxílio de autores como Flusser (2002), Santaella (2007), Souza e Silva (2006); Latour (2012) e Gumbrecht (2010). 


\section{OS HIBRIDISMOS NO AUDIOVISUAL}

É importante considerar, conforme mencionado anteriormente, que muito do fenômeno audiovisual contemporâneo que perpassa a web, os smartphones e as plataformas de streaming deve-se ao cinema, pois este instaurou-se como um modelo de pensamento da imagem e do movimento. Dubois (2004, p. 25) usa o termo "imaginário cinematográfico" como sendo algo que está impregnado em nossa maneira de falar ou de ser. "Quem, ao percorrer de carro um longo trajeto numa vasta paisagem aberta, não pensou, com a ajuda de música no rádio, numa figura de travelling mergulhando na tela panorâmica de seu parabrisa?".

Há que se ressaltar, no entanto, que os processos audiovisuais contemporâneos e suas respectivas estéticas passaram por estágios evolutivos, os quais se relacionam com a profusão das chamadas imagens técnicas. De acordo com Flusser (2002), essas dizem respeito às imagens produzidas por aparelhos, e o caráter, aparentemente, não-simbólico de tais imagens faz com que os observadores as encarem enquanto janelas para o mundo, e não enquanto imagens. Quer dizer, “o observador confia nas imagens técnicas tanto quanto confia em seus próprios olhos" (FLUSSER, 2002, p. 14). Mas, tais imagens são tão simbólicas quanto o são todas as outras imagens, ou seja, o desafio que se coloca diante das pesquisas das mídias audiovisuais é o de se decifrar e reconstituir os textos que tais imagens significam. Pois o que vemos não é o mundo, mas conceitos relativos ao mundo. Tais conceitos estão expressos a partir de processos produtivos, estéticos e semióticos que se escondem na opacidade do aparelho, de modo que o espectador vive em função da magia imagética.

Assim, deixam-se de se perceber os conceitos estéticos de mundo ali presentes, isto é, a sociedade místico-tecnológica do século $\mathrm{XXI}^{3}$ substitui a consciência histórica por uma consciência mágica proporcionada pelas imagens técnicas (tecnológicas). É possível dizer ainda, que quando essas imagens estão mais facilmente disponíveis, a um toque no smartphone ou a um toque no controle remoto da smart $\mathrm{TV}$, e em quantidade quase que infinita, esse processo ganha dimensões muito maiores do que se via anteriormente.

[...] quando os instrumentos viraram máquinas, sua relação com o homem se inverteu. Antes da revolução industrial, os instrumentos cercavam os homens; depois, as máquinas eram por eles cercadas. Antes, o homem era a constante da relação, e o instrumento era a variável; depois, a máquina passou a ser relativamente constante. Antes os instrumentos funcionavam em função do homem; depois grande

3 Termo utilizado por Ciro Marcondes Filho em seu livro "Super-ciber: a civilização místico-tecnológica do século 21”. Paulus: São Paulo, 2009. 
parte da humanidade passou a funcionar em função das máquinas. (FLUSSER, 2002, p. 21).

O cenário descrito na citação acima se evidencia na produção audiovisual de modo cada vez mais recorrente, pois os avanços científicos e tecnológicos de dispositivos e os modos de pós-produção e distribuição se colocam de forma mais incisiva enquanto referências ou critérios de manifestações e criações. Por exemplo, teoricamente, todo processo criativo surge enquanto um modo de interação humana com o mundo de modo oposto a um modo técnico. Ou seja, as estratégias criativas envolvem etapas de expressão, percepção e relação com as "coisas do mundo". Por outro lado, sabemos que os modos de interação em termos de linguagem audiovisual, de certa forma, sempre envolveram, em algum momento, a mediação técnica. No entanto, o que se percebe, hoje, é que tal mediação está se antecipando e fazendo-se presente em etapas anteriores, alterando, assim, as concepções e conceitos estéticos.

[...] ora, depois da foto e do filme, tecnologias ainda mecânicas, vieram o rádio, a televisão e o vídeo - tecnologias eletrônicas -, computacionais, a hipermídia, as redes, os dispositivos móveis, o ciberespaço em geral e as intrincadas questões colocadas pelo avanço das ciências contemporâneas. (SANTAELLA, 2007, p. 254).

$\mathrm{Na}$ esteira desse pensamento, Thomas (2006) afirma que no momento em que chegamos à era da "internet das coisas" temos atores não-humanos interagindo com humanos, mas também interagindo entre si, sem nenhuma agência humana como mediadora. Para ela, então, a pressuposta distinção entre humano e máquina vem se desfazendo cada vez mais, na medida em que ao realizarmos atividades como enviar um e-mail, trocar dados com um site ou comprar um produto pela rede, "nós estabelecemos um compromisso entre corpo, tecnologia e natureza, permitindo que nossos dados se tornem parte de uma base de conhecimento de uma organização" (Ibid, 2006, p. 388) ${ }^{4}$. De acordo com a autora, nossa característica "carnal" não faz com que fiquemos de fora dessa equação/compromisso, pelo contrário, há uma retroalimentação entre os elementos da cadeia.

Os dispositivos móveis e a conexão ubíqua constante tornam o usuário e a rede maquínica profundamente integrados, sendo que suas existências ficam quase que indissociáveis. Pang (2008 apud SANTAELLA, 2010) defende que os dispositivos móveis remodelam as relações entre usuários e tecnologia, engajando novos sentidos na interação. Diante disso, é possível afirmar que o fenômeno audiovisual contemporâneo resulta (e é

4 Tradução da autora, trecho original: "We make a trade-off between body, technology and nature by allowing our data to become part of that organization's knowledge base". 
também resultado) de expressões tecnoestéticas. De acordo com Santaella (2007), o autor Manovich definiu tais expressões a partir do termo "infoestética", o qual designa as estéticas emergentes e as formas culturais específicas de uma sociedade informacional global:

(...) portanto, a estética, nesse caso tecnológica, está voltada para o potencial que os dispositivos tecnológicos apresentam para a criação de efeitos estéticos, quer dizer, efeitos capazes de acionar a rede de percepções sensíveis do receptor, regenerando e tornando mais sutil seu poder de apreensão das qualidades daquilo que se apresenta aos sentidos. (SANTAELLA, 2007, p. 255).

Santaella afirma que as estéticas tecnológicas disseminam-se em variados formatos, gêneros e suportes, podendo se fazer presentes em "publicidades, designs de hipermídia, vinhetas de televisão, filmes documentários, efeitos especiais no cinema, nas novas formas híbridas das imagens em movimento, na moda, nas sonoridades circundantes" (SANTAELLA, 2007, p. 255-256). Daí que este estudo tematiza reflexões sobre as imagens técnicas do audiovisual extra-fílmico ${ }^{5}$ no formato trailer das produções originais Netflix, observando a dimensão algorítmica que constitui essa tecnoestética.

Dentro da lógica de um espaço híbrido habitado pela coletividade, Jarvis (2015) afirma que estamos diante de um novo ecossistema midiático. Esse novo ecossistema é composto por múltiplas companhias, blogs, mídia independente e outros produtores de conteúdo. Além dos diferentes atores presentes na esfera da produção, há também os diversos caminhos percorridos pelo conteúdo na etapa da circulação, que incluem as plataformas de redes sociais online e outros serviços, como as plataformas de streaming, cuja curadoria é realizada de forma automatizada por algoritmos.

Uma das plataformas de streaming mais relevantes no mercado, na atualidade, é a Netflix, serviço que oferece transmissão online de uma ampla variedade de séries, filmes e documentários originais e de terceiros, produzidos em diversos locais do mundo e sem comerciais. De acordo com relatório divulgado em $2019^{6}$, a Netflix possui mais de 29 milhões de assinantes na América Latina. Nos Estados Unidos, esse número ultrapassa os 60 milhões. Segundo informações apuradas pelo Portal $\mathrm{UOL}^{7}$, somente no Brasil o número de assinantes seria de 12,5 milhões. Além disso, até 2021 o serviço de streaming teria um número de cadastrados maior que a soma de todas as operadoras de TV a cabo do país. Importante

5 Audiovisual extra-fílmico diz respeito a produtos que circundam o filme e /ou as séries e, de alguma forma, orientam a leitura dos mesmos, de modo relacional (também podem ser chamados de paratextos audiovisuais).

6 Disponível em: https://www.meioemensagem.com.br/home/midia/2019/12/17/netflix-possui-29-milhoes-deassinantes-na-america-latina.html

7 Disponível em: https://tvefamosos.uol.com.br/noticias/ooops/2019/06/17/analise-netflix-tem-125-mi-deassinantes-no-pais-e-fatura-meia-globo.htm 
considerar que esse número pode ser ainda maior, pois cada cadastrado é responsável por um login e senha na plataforma e esses podem ser compartilhados entre diversas pessoas. Outro ponto importante a ser considerado é que a Netflix não demanda um aparelho de televisão para ser acessado, podendo ser utilizada em smartphones, tablets, computadores desktops e notebooks.

O funcionamento da Netflix é baseado em algoritmos. Em uma única conta do serviço é possível criar até cinco diferentes perfis de usuários. Essa divisão em perfis permite que o sistema capture variações nos interesses de consumo de cada usuário e ofereça sugestões de conteúdo cada vez mais personalizadas a cada um deles. Com uma base gigante de usuários, a empresa é capaz de reunir dados e não apenas descobrir como recomendar conteúdo específico a cada um, mas também orientar a criação e investimentos em determinados tipos de produções audiovisuais originais.

Alguns exemplos de dados que são recolhidos pela plataforma para alimentar os algoritmos do serviço: quantos usuários assistiram determinada série do início ao fim; quantos pararam no meio; qual o ponto específico de desinteresse dos usuários nesse conteúdo; quais trailers foram exibidos até o final; quantas vezes o usuário aceitou a recomendação oferecida pelo sistema; que horário do dia a plataforma é mais acessada; que tipo de temática interessa mais durante a semana; quando o usuário pausa, avança ou recua um conteúdo; qual o dispositivo utilizado para acessar o sistema; de qual região geográfica o serviço é acessado; o comportamento de "zapear" pelos conteúdos disponíveis; as buscas realizadas, entre tantos outros. "A abundância de dados de origem, medições e experimentos associados nos permite operar uma organização orientada por dados” (XAVIER; BASILICO, 2012, s/p).

Hallinan e Strippas (2016) afirmam que o processamento algorítmico afeta diretamente as práticas culturais da atualidade. Segundo os autores, a atual "cultura algorítmica" faz com que os sistemas que operam a partir dessas lógicas, como a Netflix, sejam formas de tomada de decisão cultural. Sendo assim, a tecnoestética construída pela Netflix e sua lógica algorítmica nos trailers das produções disponíveis na plataforma afetam continuamente a produção e o consumo audiovisual na atualidade. Nesse sentido, é importante compreender mais a fundo o que são efetivamente e de que forma operam os algoritmos.

\section{OPERAÇÃO ALGORÍTMICA}

Por sua definição clássica e básica, um algoritmo nada mais é do que um conjunto de regras finitas organizadas, a fim de resolver um problema específico ou executar uma tarefa 
específica. Ao executarmos em nossa mente uma série de etapas com o objetivo de resolver uma tarefa cotidiana, estamos usando uma espécie de algoritmo, ou seja, estamos estabelecendo etapas para o cumprimento de um objetivo, de maneira lógica e encadeada. Quando falamos de um algoritmo que está sendo executado por um computador, estamos falando de um conjunto de regras que foram escritas utilizando alguma linguagem de programação e que se combinam para orientar o computador a executar uma tarefa (CORMEN, 2014).

Essa lógica de funcionamento dos algoritmos se aplica à construção de um software, por exemplo. O profissional responsável por escrever o código que dá origem àquele software descreve nele todas as operações que deverão ser executadas. No entanto, uma parte extremamente significativa dos algoritmos com os quais lidamos na atualidade estão baseados em machine learning e neles, as funções que serão executadas, ou ainda, as tarefas que serão implementadas para resolver um problema, são definidas pelo próprio algoritmo.

Domingos (2017) esclarece que problemas demasiadamente longos e complexos exigiriam uma capacidade sobre-humana de um programador, logo, o algoritmo aprendiz é a solução para esse problema.

Todo algoritmo tem uma entrada e uma saída: os dados entram no computador, o algoritmo faz o que precisa com eles, e um resultado é produzido. O machine learning faz o contrário: entram os dados e o resultado desejado, e é produzido o algoritmo que transforma um no outro. Os algoritmos de aprendizado - também conhecidos como aprendizes - são aqueles que criam outros algoritmos. Com o machine learning, os computadores escrevem seus próprios programas, logo não precisamos mais fazê-lo. (DOMINGOS, 2017, p. 40).

O machine learning é um subcampo da inteligência artificial. Os algoritmos que operam dentro das plataformas de streaming são baseados em inteligência artificial, ou seja, têm capacidade de aprendizado à medida que novos inputs vão sendo colocados no sistema. Assim, conforme os gostos e interações vão mudando, o algoritmo vai aprendendo e se adaptando para sempre exibir os conteúdos que considera mais adequados para o usuário, de acordo com o perfil delimitado.

Entre as propostas que nos ajudam a compreender o atual cenário midiático e plataformizado (VAN DIJCK; POELL; WALL, 2018), estão a Teoria Ator Rede e a materialidade da Comunicação. Essa última, em específico, é responsável pelo conceito de acoplagem que nos ajuda a compreender a operação conjunta de atores humanos e nãohumanos dentro de um sistema. Ao trazermos para este trabalho o conceito de acoplagem, de 
Maturana e Varela, apresentado por Gumbrecht (2010), estamos chamando a atenção para o aspecto da materialidade da Comunicação.

Para Felinto (2006), as tecnologias da comunicação não estão limitadas a propagar ideias, mas interferem em como os espaços e territórios sociais são estruturados. Para o autor, os artefatos da comunicação são mais do que instrumentos transmissores de mensagens, eles transmitem cultura, estruturam relações sociais e ambientes humanos. Latour (2012) sugere que a materialidade não é apenas um intermediário técnico no processo comunicacional, mas um ator não-humano que transforma e opera internamente o conjunto e traz à tona a questão da agência dos objetos. Essa ação, no entanto, não é do objeto em si, sozinho, isolado, mas da associação que se dá entre ele e os outros atores envolvidos no sistema. É a associação, e, neste sentido, a própria rede e os rastros deixados pelos atores que geram um resultado específico e não a pura e simples soma das partes envolvidas no processo. Ou seja, um sistema é mais do que a soma das partes envolvidas. Com isso, o efeito de uma operação envolvendo algoritmos é mais do que o resultado da operação executada por ele. Trata-se, na verdade, do resultado da união de todos os agentes envolvidos no processo e de suas condições de operação naquele dado momento.

Segundo Latour (2012, p. 108, grifo do autor), "qualquer coisa que modifique uma situação fazendo diferença é um ator". O caminho das associações é criado pelos próprios actantes, pelo andamento das possíveis instabilidades. Para o autor, a ordem é trazida pelo desdobramento dos processos e devemos acompanhar as ações, entendendo que os humanos criam e agem com os artefatos não-humanos, mas esses também reagem sobre eles e interferem nas formas de associação finais. O homem cria o artefato, mas esse também o recria quando ambos entram em interação.

\begin{abstract}
A ANT não alega, sem base, que os objetos fazem coisas "no lugar" dos atores humanos: diz apenas que nenhuma ciência do social pode existir se a questão de o quê e quem participa da ação não for logo de início plenamente explorada, embora isso signifique descartar elementos que, à falta de termo melhor, chamaríamos de não humanos. [...] Para os sociólogos de associações, o que é novo não é a multiplicidade de objetos mobilizados por um curso de ação ao longo do caminho ninguém jamais negou que eles existam aos milhares. Novo é o fato de os objetos surgirem de súbito não apenas como atores completos, mas também como aquilo que explica a paisagem variegada pela qual começamos, os poderes supremos da sociedade, as notórias assimetrias, o rude exercício do poder. (LATOUR, 2012, p. 109 , grifo do autor).
\end{abstract}

Assim como a Teoria Ator Rede (TAR ou ANT, em inglês, Actor Network Theory), a teoria dos sistemas busca romper com a ideia de causa e efeito para explicar um fenômeno, voltando-se para as relações, interações e influências que ocorrem dentro da própria rede 
constituída pelos atores. Ao citar a teoria dos sistemas, Gumbrecht (2010) traz o conceito de acoplagem de Maturana e Varela. A ideia de acoplagem pressupõe a existência de dois sistemas e sua ocorrência pode se dar em primeiro ou segundo nível. No primeiro nível, um sistema condiciona o estado do outro e vice-versa, mas de forma finita, sempre dentro de uma sequência de possibilidades. No segundo nível, a acoplagem dos sistemas é capaz de engendrar diferentes estados de forma infinita. Ou seja, nesse caso, a acoplagem possui um caráter produtor, gerando estados novos e desconhecidos. Ao observarmos, utilizarmos e analisarmos uma plataforma de redes sociais online geramos um estado específico dessa acoplagem, no entanto, esse estado só o é por ser parte dessa acoplagem. “[...] Ao descrever a acoplagem do corpo de Nietzsche com sua máquina de escrever, devo considerar que a forma material desta máquina desempenha um papel decisivo na constituição do sentido. A máquina, enquanto forma, contribui à acoplagem”. (GUMBRECHT, 2010, p. 402).

\section{A ACOPLAGEM ALGORÍTMICA E AUDIOVISUAL NO STREAMING}

O audiovisual, também como outros sistemas, sempre foi composto pela integração de atores humanos e não-humanos. Podemos dizer que antes da mudança tecnológica que mencionamos, o audiovisual estava habituado aos seus atores não-humanos. A câmera, a película, os gravadores de som, as ilhas de edição, as primeiras câmeras eletrônicas, as mesas de edição não-lineares, os projetores, a tela do cinema, o aparelho de televisão, todos esses e muitos outros faziam parte do sistema e compunham o resultado que era apresentado ao público espectador também a partir de outros atores não humanos. Todos esses estavam em interação com a produção audiovisual dentro de um espaço controlado por ela mesma, num estúdio de cinema, numa emissora de televisão, até mesmo num espaço de produção independente e experimental. As interações se davam dentro de um sistema conhecido, tradicional e com regras estabelecidas e conhecidas. Agora, é importante compreender que outras regras foram adicionadas a essa equação, assim como novos atores, o que acaba por constituir novos sistemas de operação.

Especificamente no objeto de observação deste trabalho, a plataforma de streaming Netflix, os algoritmos são atores fundamentais para o funcionamento do sistema. São eles que, a partir dos dados coletados dos usuários, organizam, selecionam e hierarquizam os conteúdos que serão exibidos na tela, além de orientarem em quais produções originais se 
darão os investimentos ${ }^{8}$. Cada usuário da plataforma recebe uma tela inicial completamente diferente, construída a partir do que é relevante para aquele indivíduo, de acordo com o algoritmo (LATZER et al., 2016). No entanto, essa especificidade do sistema de recomendação já é conhecida e familiar dos estudos da área. O que buscamos chamar a atenção aqui é para a transformação gerada pela lógica de produção e exibição dos trailers operante dentro desse sistema de apresentação dos conteúdos da plataforma.

Quando o usuário acessa o sistema da Netflix, uma tela com várias opções de conteúdos é exibida para ele. Conforme o movimento do cursor do seu dispositivo vai mudando, muda também o conteúdo que é exibido na tela ao fundo dos ícones das obras. Esse conteúdo normalmente corresponde ao trailer da obra sobre a qual o cursor do dispositivo se localiza naquele momento. Isso que aqui começamos chamando de trailer, no entanto, possui uma série de características diferentes que variam conforme o tipo de obra, se atual ou antiga, se original da plataforma ou de terceiros. Nossa observação recai sobre o conteúdo exibido para as obras originais da Netflix.

A fim de aprofundar a discussão do ponto de vista estético, é preciso elucidar que a compreensão que assumimos do trailer vincula-se à perspectiva contra hegemônica. Isso quer dizer que entendemos o trailer para além de sua função meramente publicitária.

Contemplar o trailer como um texto significa assumi-lo como um tecido cujos sentidos não são essencialistas, mas que se fazem em um jogo de integração de fragmentos, que se complementam nas sínteses, nas remissivas, nos traços e em suas redes intertextuais (SILVA; IUVA, 2013, p. 311).

Assim, o trailer diz respeito a uma operação de composição audiovisual cuja estética pode adequar-se a um dado padrão global de produção, mas, ao mesmo tempo, é possível identificar a existência de elementos fluidos que escapam aos modelos pré-concebidos. O que vem acontecendo na plataforma de streaming Netflix é uma apropriação de noções gerais da função do trailer - oferecer ao usuário espectador um vislumbre do que será a série e/ou filme -, atrelada a operações tecnoestéticas mais complexas, uma vez que os elementos formais e estruturais narrativos que constituem um trailer padrão não são necessariamente utilizados ${ }^{9}$.

8 Um dos casos mais famosos e recorrentes sobre a criação e produção original Netflix orientada pelo uso de algoritmos e leitura de base de dados é a da série House of Cards. Disponível em https://neilpatel.com/blog/how-netflix-uses-analytics/ . Acesso: 20 jun. 2020.

9 De acordo com Iuva (2007, p. 103), distinguem-se três momentos constitutivos da estrutura narrativa de um trailer: 1. Geralmente, em primeiro lugar, aparecem os logotipos ou marcas da distribuidora e da produtora do filme. É o selo de identificação ou marca de fábrica do filme. (início); 2. No segundo momento, articulamse os fragmentos do filme, as cenas, os diálogos, as imagens, palavras (textos, frases de efeito), as narrações, músicas, enfim, todo o conjunto daquilo que sustenta o trailer. (meio); 3. E, por último, o encerramento com 
Diante disso, identificamos uma paisagem diversa nos trailers das produções originais Netflix:

a) variações no tempo de duração (existem trailers de 1 minuto, 2 minutos e também de 3 minutos);

b) algumas produções ganham mais de uma versão de trailer, bem como vídeos adicionais - geralmente aquelas com maior investimento e sucesso junto ao público, por exemplo, a série Stranger Things;

c) há também uma versão ainda mais curta do trailer, conhecida como teaser, que é utilizada em alguns casos, por exemplo, para a terceira parte da série La Casa de Papel há um teaser de 15 segundos, enquanto que para a segunda temporada de Stranger Things, um teaser de 30 segundos.

Além das diversificações acerca dos modos de composição, é importante destacar que assim como as sugestões de conteúdo variam de acordo o perfil de cada usuário, os trailers que são exibidos na tela de fundo das produções originais Netflix também variam. Por exemplo, o tipo de trailer exibido na tela inicial da plataforma varia caso o usuário já tenha assistido à respectiva série ou não. Para usuários que já demonstraram interesse, são exibidos conteúdos mais aprofundados e para usuários que ainda não tiveram contato com a produção, o trailer exibido busca apresentar o produto (LATZER et al, 2016).

Isso que estamos tratando é uma criação e um uso do trailer que ocorre de modo muito distinto daquele feito pelo cinema, pois a lógica de operação está sustentada em dois novos fatores: os algoritmos e os hibridismos audiovisuais. A combinação desses aspectos produz uma espécie de tecnoestética trailerífica orientada por dados. Para Santaella (2007), o cenário desses processos audiovisuais contemporâneos, implica

[...] discutir, isso sim, as condições propiciadas pelos aparelhos, dispositivos e suportes tecnológicos que, desde a invenção da fotografia até os hibridismos permitidos pelo ciberespaço e pelas invenções tecnocientíficas contemporâneas, de modo cada vez mais vertiginosos, vêm ampliando e transformando as bases materiais e os potenciais dos modos de produção estéticos. (SANTAELLA, 2007, p. 255).

Sendo assim, a estética tecnológica que recobre os trailers da Netflix envolve uma operação técnica com conhecimento para realização de determinada tarefa. Quer dizer, tratase de um saber, de uma habilidade, "uma bateria de procedimentos que se criam, se aprendem, se desenvolvem" (SANTAELLA, 2007, p. 257). Aliando-se às operações algorítmicas, as 
habilidades passam a ser uma atividade coletiva internalizada pelas linguagens que nos circundam. Ou seja, passam a ser "máquinas semióticas", uma vez que operam uma técnica introjetada de sentidos e significados que circulam no universo midiático. À medida que os dispositivos técnicos se ampliam e expandem as possibilidades de produção de imagens audiovisuais, assim, também, se altera a estética e os sentidos ali presentes.

O estudo da estética do ponto de vista tecnológico implica, portanto, no reconhecimento, cada vez mais nítido, das misturas de suportes, tecnologias e linguagens. Isto é, perpassa pelas noções dos hibridismos, uma vez que, diante do surgimento de novas tecnologias as anteriores não desaparecem, do contrário, somam-se, complementam-se. Por isso, quando se pensa a dimensão estética do audiovisual, há que se considerar um cenário em que fotografia, cinema, vídeo, animação, design e computação coexistem naquilo que Manovich (2006 apud SANTAELLA, 2007, p. 264) considera "vários híbridos e mutações que passaram por vários filtros e ajustamentos manuais até adquirir um look estilizado, uma aparência gráfica mais chapada, uma cor mais saturada, etc.”. Por exemplo, a indústria cinematográfica e a indústria dos games, apesar de competirem em um mercado bilionário, travam relações estéticas de linguagem de forma simbiótica, promovendo e "remediando" uns aos outros, adaptando uns dos outros histórias, técnicas e personagens, tanto para as telas dos filmes quanto dos games.

A partir dessa relação, podemos dizer que os trailers das produções originais da Netflix vêm trabalhando com composições imagéticas e modelos discursivos - tipos de planos, enquadramentos, montagem, ritmo, foco narrativo etc. - híbridos: de um lado influenciados pela longa tradição narrativa e persuasiva dos trailers de cinema, e por outro lado alicerçados pela lógica algorítmica. Ou seja, o movimento de remediação, entendido enquanto um processo de apropriação de aspectos de diferentes lugares acontece em qualquer direção de convergência tecnológica.

Quando falamos em convergência, nos referimos, além dos processos tecnológicos que unem múltiplas funções dentro dos mesmos aparelhos, também a um processo cultural e estético, a partir de pedaços, fragmentos extraídos dos mais diversos fluxos audiovisuais e combinados em outros. Esse processo que está em curso nas plataformas de streaming produz novos sentidos estéticos a partir das convergências midiáticas:

Nos últimos anos, vimos como os celulares se tornaram cada vez mais fundamentais nas estratégias de lançamento de filmes comerciais em todo o mundo; como filmes amadores e profissionais produzidos em celulares competiram por prêmios em festivais de cinema internacionais; como romancistas japoneses serializaram sua obra via mensagens de texto; como gamers usaram aparelhos móveis para competir em jogos de realidade alternativa. (JENKINS, 2009, p. 31). 
Tais recorrências e outras ainda, como festivais de trailer, as produções e divulgação de making off na internet e canais do YouTube, a produção de conteúdo dos originais Netflix, as especificidades da construção de interfaces e artes específicas nos menus em plataformas como Netflix, Amazon Prime, Apple+, bem como o desenvolvimento e aperfeiçoamento dos créditos de abertura tanto no cinema quanto nas séries, conduzem os questionamentos para um futuro estudo acerca de um movimento estético tecnológico na produção audiovisual. Existe uma lógica tecnoestética que perpassa as mídias audiovisuais, e percebemos essa lógica inserindo-se fortemente nas plataformas de streaming através do uso de dados orientados por operações algorítmicas.

Identificamos também neste processo uma perspectiva cultural, ou seja, o serlinguagem da contemporaneidade é da ordem de uma dada produção audiovisual que se enuncia por operações algorítmicas que influenciam e produzem uma estética de fluxo trailerífico. Em outras palavras, as condições tecnológicas possibilitam que o audiovisual se manifeste em plataformas streaming com um atravessamento tecnoestético do trailer.

Quantas vezes já ouvimos alguém dizer que passou horas navegando no Netflix e não escolheu nenhum programa? É possível dizer que assistir à Netflix implica, em certa medida, assistir (e/ou navegar) pelo seu fluxo de conteúdo enunciado pelos trailers. As condições contemporâneas mostram-se contaminadas por uma estética tecnológica, que não se restringe a espaços e círculos fechados, mas que alcança audiências ilimitadas social, regional e nacionalmente.

\footnotetext{
O telefone, o telégrafo, o cinema, o rádio, a televisão, o videocassete, os CDs e os DVDs desenvolveram-se com tecnologias culturais que podiam funcionar mundialmente. Sua tendência de cruzar todas as fronteiras é inerente, tendência que a mídia telemática acentuou ainda mais. Seus usuários não se veem como espectadores e ouvintes, mas como participantes de um evento global, jogadores num contexto interativo que aprendemos a designar "comunicações". Nesse nosso mundo somos confrontados não com aparelhos técnicos individuais, mas com sistemas técnicos construídos com elementos múltiplos, e, no sentido exato do termo, com tecnologia. (ZIELINSKI, 2006, p. 304).
}

Novas práxis artísticas, midiáticas e científicas penetram mercados já desenvolvidos, discursos formalizados, canais de distribuição e de exibição, ou seja, trata-se de um movimento que extrapola os limites das experiências individuais. Pois o que se observa é que a "mutação hipermoderna se caracteriza por envolver, num movimento sincrônico e global, as tecnologias e os meios de comunicação, a economia, e a cultura, o consumo e a estética (LIPOVETSKI; SERROY, 2009, p. 23). Assim, os trailers das produções audiovisuais 
originais Netflix configuram o que podemos chamar de um mixtum compositum ${ }^{10}$ de estéticas que constituem conceitos específicos de uma práxis cultural. O deciframento de que um conceito estático e identitário de trailer não dá conta da experiência que temos com o ecossistema dos algoritmos e das imagens técnicas do Netflix aponta para a necessidade, cada vez maior, de compreensão dessa alquimia contemporânea que opera as bases tecnológicas em construções estéticas, por vezes instáveis, efêmeras, mas em constante transformação.

\section{APONTAMENTOS FINAIS}

A discussão teórica apresentada neste trabalho buscou evidenciar o debate atual sobre algoritmos e a tecnoestética audiovisual dentro de uma visão que une a Teoria Ator-Rede, o conceito de acoplagem, a materialidade da comunicação e a Teoria dos Sistemas. O objetivo de incorporar esses autores ao diálogo é provocar um debate onde o audiovisual seja contemplado como parte de um sistema, não como o ator principal, mas sim como membro de uma acoplagem que se torna mais complexa, envolvendo uma série de atores humanos e nãohumanos, entre eles algoritmos que interferem cada vez mais nos espaços pelos quais circulamos e as plataformas que utilizamos para comunicação e consumo de conteúdo. Os algoritmos, enquanto agentes não-humanos, são capazes de interferir nas ações de muitos sistemas compostos de diferentes atores, influenciando uma série de possíveis resultados técnicos e estéticos.

Por conseguinte, o presente estudo demonstrou que todas nossas relações com as coisas do mundo e com os outros são cada vez mais mediatizadas por uma quantidade de interfaces algorítmicas nas quais as imagens técnicas não cessam de convergir, de se comunicar, de se interconectar. Assim, este trabalho, alinha-se à proposta do dossiê "Cinema, Mídia e Tecnologia - narrativas e linguagens nas paisagens digitais", já que buscou dar conta, de um modo geral, das reflexões acerca dos meios audiovisuais e as convergências tecnológicas algorítmicas na estética das imagens técnicas. Mais do que pensar em formatos, gêneros e suportes (numa perspectiva identitária rígida), há que se pensar em uma arqueologia estética do audiovisual, que se manifesta em diferentes territórios.

$\mathrm{Ou}$ seja, buscamos destacar neste texto justamente os aspectos fundamentais da associação, da acoplagem e da estética para que possamos entender a função dos algoritmos na produção e no consumo audiovisual contemporâneo. O papel fundamental dos dados e, com eles, das bases de dados aponta que a plataforma Netflix vem operando fortemente essa

\footnotetext{
10 Termo utilizado por Zielinski (2006, p. 304) para definir a arte midiática.
} 
lógica. Além de nos perguntarmos qual o papel dos algoritmos para entender os resultados gerados por eles, precisamos nos perguntar a quem servem os algoritmos e que dados estão sendo tratados por eles, para aí sim começarmos a ter uma noção mais completa das consequências que nos esperam pelo caminho. Por fim, é necessário nos perguntarmos também o papel que o audiovisual pode exercer nessa associação e como ele pode agir enquanto ator participante desta acoplagem, deixando exposto, talvez, de forma mais clara, a sua especificidade enquanto instituição fundamental das noções de estética e cultura.

\section{REFERÊNCIAS}

CORMEN, T. Desmistificando algoritmos. Rio de Janeiro: Elsevier, 2014.

DOMINGOS, P. O algoritmo mestre. São Paulo: Novatec, 2017.

DUBOIS, P. Cinema, vídeo, Godard. São Paulo: Cosac Naify, 2004.

FELINTO, E. Passeando no labirinto: ensaios sobre as tecnologias e as materialidades da comunicação. Porto Alegre: PUCRS, 2006.

FLUSSER, V. Filosofia da caixa preta: ensaios para uma futura filosofia da fotografia. Rio de Janeiro: Relume Dumará, 2002.

GAUDREAULT, A; MARION, P. O fim do cinema? Uma mídia em crise na era digital. Campinas, SP: Papirus, 2016.

GUMBRECHT, H. U. O campo não hermenêutico ou a materialidade da comunicação. Teresa Revista de Literatura Brasileira, São Paulo, n. 10/11, p. 386-407, 2010.

HALLINAN, B.; STRIPHAS, T. Recommended for you: the Netflix Prize and the production of algorithmic culture. New Media \& Society, v. 18, n. 1, p. 117-137, 2016.

IUVA, P. de O. As estratégias contratuais do trailer cinematográfico. Animus: Revista interamericana de comunicação midiática, Santa Maria, v. VI, n. 2, jul,/dez, 2007.

JARVIS, J. Geeks bearing gifts: imagining new futures for news. [S. l. : s. n.], 2015. Disponível em: https://medium.com/geeks-bearing-gifts. Acesso em: 15 abr. 2015.

JENKINS, H. Cultura da convergência. São Paulo: Aleph, 2009.

LATOUR, B. Reagregando o social: uma introdução à teoria do ator-rede. Salvador: UFBA : USC, 2012.

LATZER, M.; HOLLNBUCHNER, K.; JUST, N.; SAURWEIN, F. The economics of algorithmic selection on the Internet. In: BAUER, J. M.; LATZER, M. Handbook on the economics of the internet. UK: Edward Elgar, 2016. 
LIPOVETSKY, G.; SERROY, J. A tela global: mídias culturais e cinema na era hipermoderna. Sulina: Porto Alegre, 2009.

ORBEN, D. J. Imagens técnicas: origem e implicações segundo Vilém Flusser. Comunicação \& Informação, v. 16, n. 1, p. 113-126, jan/jun 2013.

SANTAELLA, L. A ecologia pluralista da comunicação: conectividade, mobilidade, ubiquidade. São Paulo: Paulus, 2010.

SANTAELLA, L. Linguagens líquidas na era da mobilidade. São Paulo: Paulus, 2007.

SILVA, A. R.; IUVA, P. de O. As semioses do trailer da publicidade à experiência estética. Revista Famecos, Porto Alegre, v. 20, n. 2, p. 310-336, maio/ago. 2013.

SOUZA E SILVA, A. de. From cyber to hybrid: mobile technologies as interfaces of hybrid spaces. Space and Culture, v. 9, n. 3, 2006.

STAM, R.; SHOHAT, E. Teoria do cinema e espectatorialidade. In: RAMOS, F. P. Teoria contemporânea do cinema. Pós-estruturalismo e filosofia analítica. São Paulo: SENAC-SP, 2005 .

THOMAS, S. The end of cyberspace and other surprises. Convergence: The International Journal of Research into New Media Technologies, v. 12, n. 4, 2006.

VAN DIJCK, J.; POELL, T.; WAAL, M. de. The platform society. New York: Oxford University Press, 2018.

XAVIER, A.; BASILICO, J. Netflix Recommendations: beyond the 5 stars. The Netflix Tech Blog, 2012. Disponível em: https://netflixtechblog.com/netflix-recommendations-beyond-the5-stars-part-1-55838468f429. Acesso em: 20 abr. 2019.

ZIELINSKI, S. Arqueologia da mídia: em busca do tempo remoto das técnicas do ver e ouvir. São Paulo: Annablume, 2006. 